\title{
CREANDO: Tool for creating pervasive games to increase the learning motivation in higher education students

\author{
Jeferson Arango-López ${ }^{\mathrm{a}, \mathrm{b}, \square}$, Carlos C. Cerón Valdivieso ${ }^{\mathrm{a}}$, Cesar A. Collazos ${ }^{\mathrm{a}}$, \\ Francisco Luis Gutiérrez Vela ${ }^{\mathrm{b}}$, Fernando Moreira ${ }^{\mathrm{c}, \mathrm{d}}$
}

${ }^{\text {a }}$ University of Cauca - FIET, Street $5 \mathrm{~N}^{\circ}$ 4-70, Popayán, Colombia

${ }^{\mathrm{b}}$ University of Granada, ETSIIT, Department of Languages and Informatics Systems, Street Periodista Daniel Saucedo Aranda, s/n, 18071 Granada, Spain

c Univ Portucalense, REMIT, IJP, Rua Dr. António Bernardino Almeida 541-619, 4200-072 Porto, Portugal

${ }^{\mathrm{d}}$ IEETA, Univ Aveiro, Aveiro, Portugal

\begin{tabular}{|c|c|}
\hline ARTI C L E I NFO & $\mathrm{ABST} \mathrm{RACT}$ \\
\hline $\begin{array}{l}\text { Keywords: } \\
\text { Pervasive game } \\
\text { Narrative } \\
\text { Learning motivation } \\
\text { Digital transformation }\end{array}$ & $\begin{array}{l}\text { The pervasive games (PG) have had a great reception in recent years. This kind of games com- bines the } \\
\text { virtual world with the real world to generate extensions of reality in terms of time, space and social } \\
\text { interaction. These extensions have involved users in experiences as varied as those exposed by } \\
\text { augmented reality and the location of the player or mixed reality scenarios. In the educational context, } \\
\text { games have been integrated little by little into learning processes. Specifically, PG have shown to } \\
\text { have a higher level of immersion in people's daily activities. Therefore, a greater impact is generated } \\
\text { when integrating the technologies of the PG and the narrative of a story that is told through the gaming } \\
\text { experience. In order to explore some fields, we focus the study on the narrative and geolocation applied to } \\
\text { close spaces, it is a way of giving an enriched experience to the player through a digital transformation } \\
\text { perspective. For this reason, it is necessary to have a platform that allows the creation and edition } \\
\text { of PG based on narrative to increase the motivation of higher education students. This article describes } \\
\text { the creation of a platform that integrates tools for creating stories and editing narrative content in the game } \\
\text { experiences. The main objective is focused on increasing the motivation of students in educational } \\
\text { processes. Specifically, the platform allows the creation of pervasive gaming ex- periences in closed } \\
\text { spaces on university campuses. In addition, the results of a test case developed with the platform and its } \\
\text { validation through statistical tools and gameplay metrics are exposed, thus demonstrating the increase in } \\
\text { students' motivation through the use of PG. }\end{array}$ \\
\hline
\end{tabular}

\section{Introduction}

PG have had a growing popularity in recent years, a factor that has influenced this trend are the advances in the field of mobile technologies, their overcrowding, wide access, cost reduction, and computational performance. All this has allowed to offer users new experiences that in previous times were only in their imagination. At present, powerful mobile platforms allow users to be aware of their context, have multiple media and interact with their environment (Viana et al., 2014). This has allowed to break the limits of the game world, and a mixture between the physical world and the virtual world has been presented. A definition of pervasive play has 
been presented by Arango-López et al. (2018), which focuses on the enrichment of the experience for the player by expanding the boundaries of the magic circle and the inclusion of the real world.

The development of this kind of experience has been enriched through the use of technologies such as detection sensors for the player's location and augmented reality. In this sense, the technologies support the tracking of scripts with an enriched game ex- perience for the users, which becomes a common thread of the game story, which is in charge of transmitting the author's intention and directing the interactions of the user for its use (López-arcos and Gutiérrez Vela, 2016). Performing the synergy among these areas of knowledge to obtain a pervasive experience is not a formal and defined procedure. On the contrary, as in most scenarios where software is developed, it is a custom-made task. This is one of the main reasons for the high cost of developing this kind of experience. From the industry and from the academy, there have been significant but not cohesive efforts in terms of tools for developers and proposals for frameworks (Arango-López et al., 2017).

From an educational perspective, this kind of support has been integrated little by little. Although, the games have been applied in its great majority in early stages of education, and of course, they have not replaced traditional methodologies, on the contrary, games are a support for them and provide added value to these methodologies. In the case of higher education, several challenges have been found in knowledge processes, incorporation into university life and learning from different areas of knowledge. Thus, it is necessary to have gaming experiences that provide new ways of performing the activities previously mentioned. This, with the main objective of increasing the motivation and feeling of immersion of students in the learning processes.

The development of the CREANDO platform emerges as a first step to optimize the development of gaming experiences based on pervasive narrative. Specifically, the tool allows the generation of experiences in closed spaces, since these are those found in higher education institutions. This is achieved through the integration of free and open source tools that allow for a cohesive experience development environment through a platform for creating and editing stories and support for the deployment of multiple media and interaction with the environment through increased reality (IR), indoor location with Beacons, presentation of information using QR codes, video, HTML code, images, among others. The CREANDO platform has been validated through a test case, supported by statistical tools prior to and following the use of the experience by students. In addition, gameplay metrics have been applied in different aspects, which has allowed us to know the strengths and point to strengthen in future work. The attributes of the gameplay have been evaluated and there is a relationship between the pervasive games and the motivational attribute generated by the developed prototype.

\section{Background}

\subsection{Game}

Classical definitions of formal games such as the one presented by Huizinga (1944) in the first part of the 20th century, define the verb to play as a free activity that is outside of ordinary life and also as an unserious action, but at the same time it absorbs player intensely and completely. This was a definition according to the time, where games were created and played in the physical world making use of the properties of the real world as the objects used and the spaces where they were developed (Magerkurth et al.,

2005). Given the advance of technology, this definition would be adapted in principle, from a completely virtual perspective to take advantage of the overcrowding and decrease in the costs of computers. Then, the same phenomenon occurred in mobile devices where in less than a decade, this technology, coupled with advances in wireless transmission, has evolved rapidly. Finally, at present, the means are provided for the development of applications that break the boundaries between the physical world and the virtual world (Arango-lópez et al., 2017).

\subsection{Pervasive games (PG)}

PG are characterized by being played when and where the player wishes, taking into account the presence of some limitations of the same devices as availability or not of connection to the Internet, or battery life of mobile devices. Despite these limitations and without distinction of the context of application, its main objective is to attract and keep the player presenting an enriched game experience, which may or may not be used for learning, recreation or relationship with their environment (Hinske et al., 2017).

In addition, it can be said that pervasive games are made up of components that work together and are the ones on which the narrative is based. These components are the devices, the context, social interaction, time, spaces, realities and multiple media as proposed by Arango-lópez et al. (2017). The incorporation of the narrative in the PG becomes a fundamental part when the edu- cational process is taken into account at a higher level, this is because the young people look for challenges and purposes that guide them through their daily activities. In this sense, the narrative is considered as the succession of events with the potential to transmit events through the media, which unites the different components in a coherent and satisfactory story for the user, which gives rise to a pervasive narrative (Stach and Schlindwein, 2012). The narrative is the main component that allows the digital transformation in the education context from a pervasive game telling a story that content a knowledge in a different way, unlike the traditional methods.

Taking into consideration previous studies and to provide clarity about the main components of the pervasive games, next it is presented the fundamental elements of the PGs and their relationship (See Fig. 1). In that image, is possible to identify the expansions of PG (time, space and social interaction), which can be achieved with the use of mobile devices in a specific context (in this case is applied in the educational context). Besides, the different realities of the world and the crossmedia material are presented. The main component is the narrative, which joins the elements afore mentioned. 


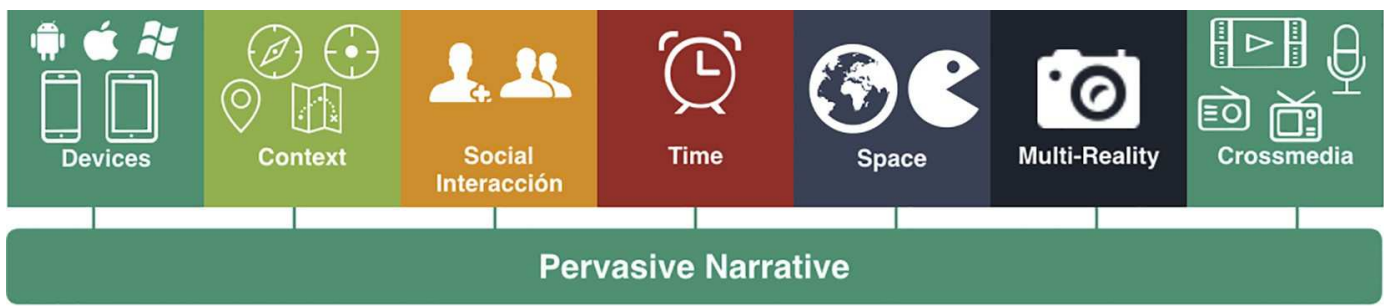

Fig. 1. Componentes principales de los Juegos Pervasivos.

\subsection{Games in the education}

Games can make the educational process more fun and enjoyable, and can motivate students to be more active in class (Tüysüz, 2009). This is possible thanks to the stories told, which can have real content, as they can also be totally virtual (Jantke and Hume, 2015), which arouses additional interest in students.

The Game-Based Learning (GBL) promises to present a new approach in university education, since with traditional methodol- ogies such as reading and writing generate difficulty in the development of tasks and activities (Kuk et al., 2012). For this reason, the motivation level of the students is reduced. Education is fundamental in the progress of society and consequently affects each of the individuals that compose it. Every day we seek to improve the teaching and learning process in the different stages of education. In higher education, there are traditional methodologies that are supported by computer equipment that allows integration with emerging technologies. But, the inclusion of gaming experiences in teaching and learning processes at this level has not been in- corporated in a good way.

The motivation for learning expressed by students of higher education should be high to a great extent, this is because they are the areas of knowledge that each student chose for their life. But, this is not completely true, since in many occasions the teaching methodologies are boring for this population that lives every day with access to cutting-edge technologies. Thus, games emerge as a possibility to provide a better learning experience and increase the level of motivation in students. This can be seen from the performance of children who enjoy performing tasks through the use of games (Stach and Schlindwein, 2012). Thus, teachers can rely on games to introduce new teaching methods in their classrooms. Specifically, when talking about PG, by using its special features they provide an enriched experience to the people who take the players to have an immersion in the history of the game.

\subsection{Narrative in the pervasive games}

Technologies are the fundamental point of support for the user's immersion in the game experiences through stories defined in it. That is the pillar on which the pervasive narrative is based. Nowadays, videogames transmit the story to the players as a multi sensorial experience making use of the narrative.

The narrative turns players into the protagonists of the story (Padilla-Zea et al., 2014). Interactivity is the special feature acquired by the narrative in games. Meadows (2002) explains the narrative as "a representation of characters and actions in which a reader can affect, choose or change the plot." According to this definition, depending on the actions of the player, a different path will be presented in which there must be a formally defined history and an experience according to the user, which must be considered in the design and structure of the story by the creator (López-Arcos et al., (2016)).

The pervasive narrative can be represented by graphs, where the content is structured by nodes linked by links (López-arcos and Gutiérrez Vela, 2016). The nodes represent the scenes to be presented throughout history. Given that the creation of a narrative is a highly abstract task, in our work, we consider a representation model of the geolocalized narrative designed by López-arcos and Gutiérrez Vela (2016). They define the narrative model (See Fig. 2) that allows creating stories to maintain the balance between author control and player freedom.

\section{Related work}

It is important to consider that previous efforts have been made to build digital tools that support the teaching-learning process. However, these efforts have focused on primary and infant education. On the part of higher education, there are some examples of digital games that support communication processes between teachers and students. But, in our case, we have not found a platform to create and maintain pervasive narrativebased game experiences, let alone focus on increasing students' motivation through the characteristics of this kind of games.

In the field of games applied to education, there are several examples. But for PGs, there has been a lower relation, this is due to the fact that the necessary technology has been developed in recent years. Some of the academic papers with the best solution approaches to the problems are explained below.

LAGARTO, created by Maia et al. (2017), who propose and develop a tool for the construction of games based on the location of the player with support for augmented reality. This tool is composed of a web environment for the creation and management of games. In addition, an application to track the position of players. The main objective of the tool is to provide a software solution that offers non-programmers the possibility of designing, building and executing mobile games based on the location of a player or 


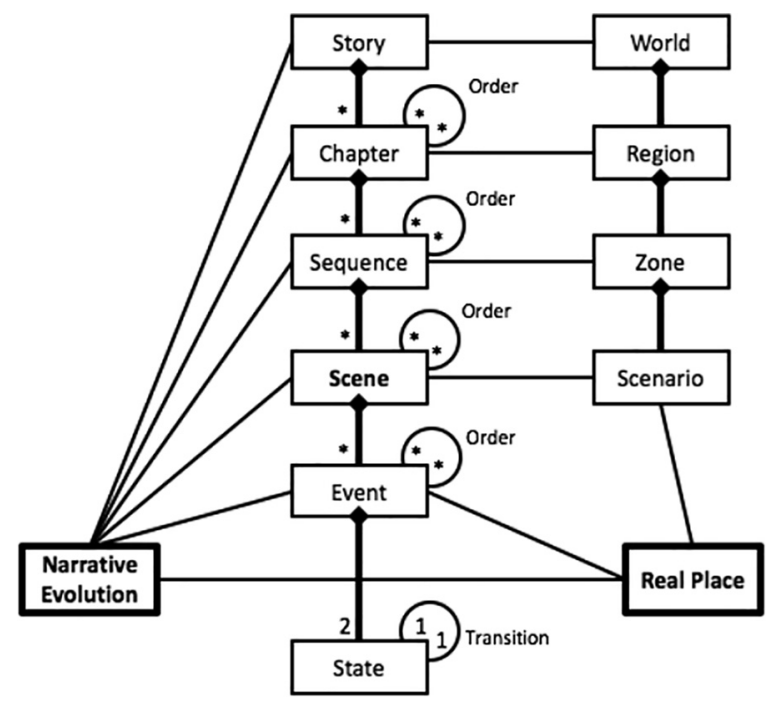

Fig. 2. Geolocalized narrative model for games.

multiple players through graphic notation. Also, consider with the possibility of ordering missions and game mechanics. The above generates a flexible way to define multiple game flows. One of the differences with our proposal is that it does not have a way to monitor the execution of the games. Additionally, compared to CREANDO, it does not define the proper characteristics for the edition of pervasive games focused on the narrative that allows the players to follow a script and a story that gives them a better experience. Consequently, the immersion experienced by the player is low level. On the other hand, there is no definition of indoor location either, since it has only been considered with GPS location in open spaces.

Also, we found fAR-Play, developed by Gutierrez et al. (2011). They present the implementation of a framework for the creation of alternate/augmented reality games for games guided by the treasure hunt metaphor. That is to say, the framework is focused on this kind of games based on position, which is supported for outdoor location under GPS and for interiors in bar and QR codes. The framework is composed of four main modules, one of them is a mobile application through which players interact with the game and a website where the state of the game is reflected. Another of the modules is the game engine where the logic of the game remains and is maintained. In addition to a tool module for the support of virtual worlds, for the mapping of the interactions between real and virtual world. In comparison with our proposal, the difference is found in the definition of narrative for gaming experiences, since fAR-Play does not have a module that allows the definition of scripts and interactions during the story, nor does it support the creation of PG with its characteristics of expansion.

Along this same line, we find WeQuest, presented by Macvean et al. (2011). This is a tool for the creation of augmented reality games based on geolocation with user-generated content. The platform has been designed with the aim of increasing the accessibility of location-based augmented reality games through three components. One of them is the game engine, which allows you to download and execute geolocated stories on mobile devices. Another component is a tool for creating stories for the user. The final component is the localization translation that adapts the stories to new areas different from those in which the story has been designed, making it possible for them to be played anywhere. In comparison with CREANDO, like the other proposals, it does not have the definition of narrative within the core of pervasive experience, that way the level of motivation and immersion within games is diminished.

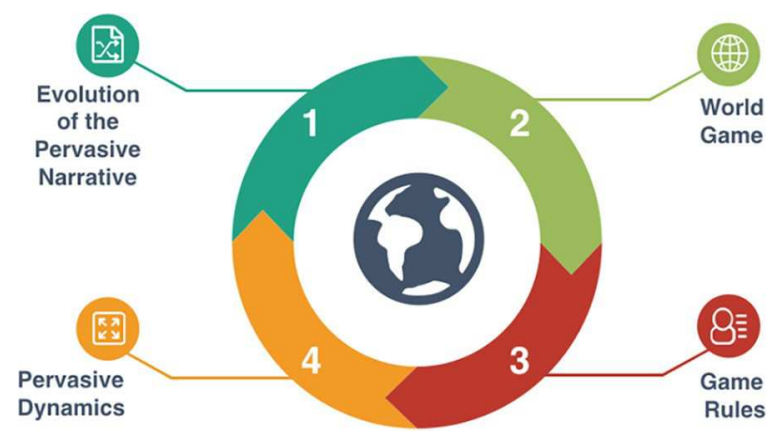

Fig. 3. Cyclic model of GeoPGD methodology. 


\section{Creando}

The CREANDO platform is designed with the directives provided by the GeoPGD methodology (See Fig. 3), which divides the design and development of a geolocated pervasive gaming experience in 4 phases. 1) Pervasive Narrative: this phase serves to define the script of the story, the characters, elements and scenarios that take part in the execution of the game, allowing each of these components to evolve to expand the initial narrative. 2) Game World: due to the pervasiveness, the game world breaks the virtual boundaries and integrates with the reality, offering the possibility of realizing a mixed world for the environment of execution of the game experience. 3) Gameplay: in this phase the rules that will govern the narrative, the world of the game and the actions of the player are defined. It is possible that these rules evolve, be modified or removed. 4) Pervasive Dynamics: in this phase everything related to the player's experience, the environment and the mechanics of the game are built up.

\subsection{Analysis}

The CREANDO platform arises from the need to create and edit pervasive gaming experiences based on narrative and localization in closed spaces. For this, as mentioned above, the state of the art and the related works were reviewed. Departing from LAGARTO as one of the best platforms that approaches to the exposed problem. We wanted to implement the platform with the desire to adjust and adapt some of its features and add others. To solve this problem, this application emerges as an effort to create a platform that integrates tools for story editing and content editing with the aim of being a first approximation for the union of these areas. In particular, for the creation of pervasive gaming experiences in closed spaces focused on the automation of tasks of the domain of software engineering and the speeding up in the development of this kind of experience.

The main objective of the study is focused to provide a solution that allows users with technical knowledge of programming the possibility of designing, constructing and executing pervasive experiences based on location, with the possibility of defining the story through the narrative, the game-play, the mechanics and dynamics of the pervasive gaming experience in an educational context.

\subsection{Design and implementation}

In the design of CREANDO, different tools were used in each of its main components. Taking into account the Core, an admin- istration panel was created where it is possible to create and edit the different game experiences (Front-End). In this administration panel, you can add audio content, video images, HTML code, Accessible information through AR and QR codes, among others. In addition, it allows the communication and transportation of information through web services. The interaction with the logic is given through an API that is related to the Back-End, where the access to the data is found. The information is stored in 2 different databases (Users and Games) to separate the access credentials and data of the games and the interaction of the players. This is presented in the architecture diagram shown in Fig. 4.

Specifically, in the Back-End, we have the authentication of administrative users through access to data through an ORM (Object Relational Mapping), this ORM also allows access to the data of the games stored in the second database.

Focused on the creation of the platform, the efforts focused on finding and adapting the best tools available for the optimization of the results in the gaming experiences and that would not generate high costs for the research.

In this same line, in order to present the technologies used in the implementation of CREANDO, Fig. 5 has been constructed, showing the main components and the elements that are part of the administrator defined in Fig. 4, which contains tools that support the necessary features in pervasive games, these are: Twine JS, ARJS, the Google Beacon tool and the QR Code-Reader. These tools are used by the mobile application through web services to show the content to the player.

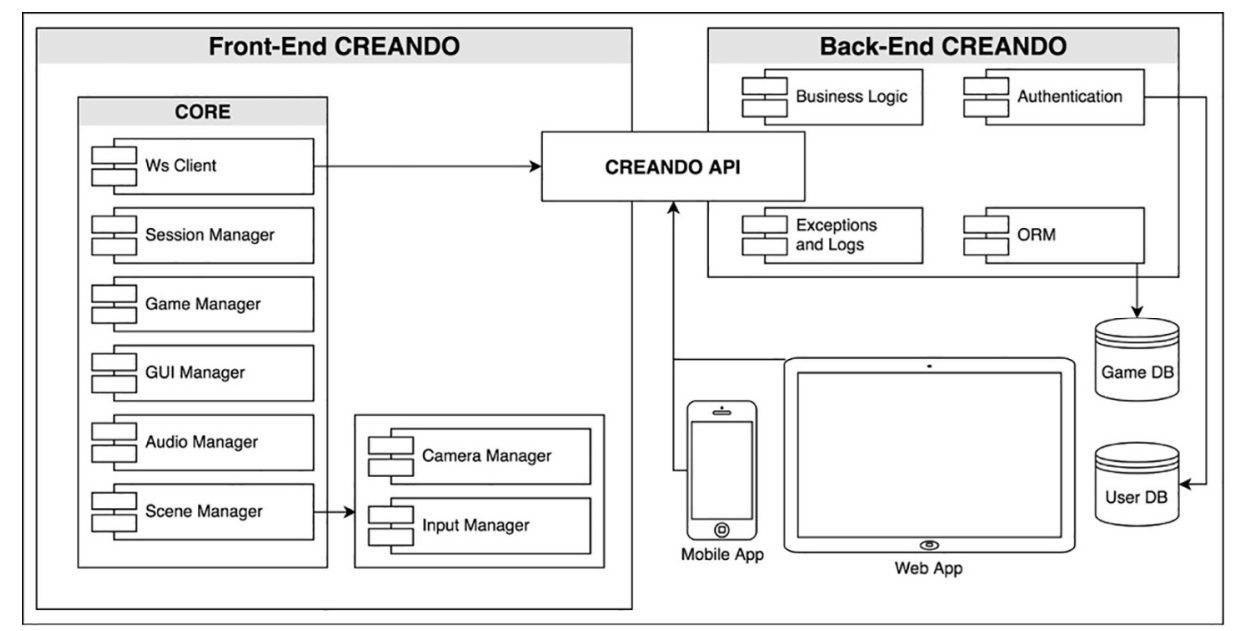

Fig. 4. Architecture design of CREANDO by modules. 


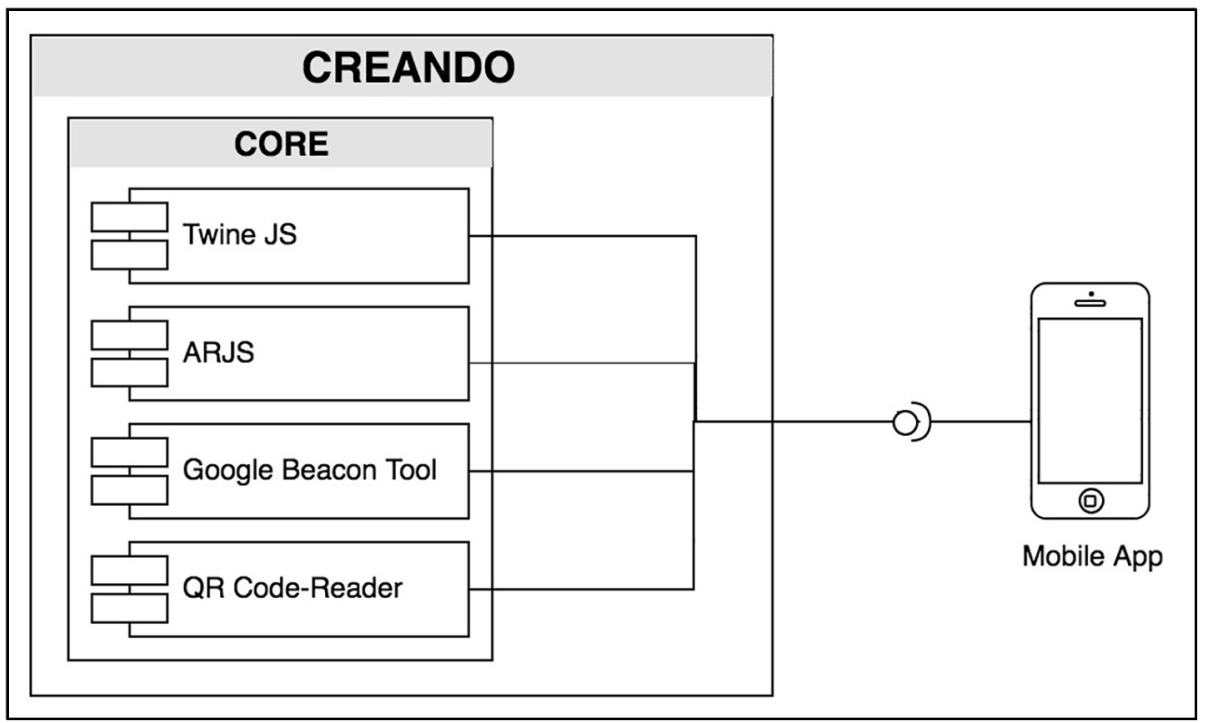

Fig. 5. Components of the administration panel in CREANDO being consumed by the mobile app.

\subsection{Operation}

The functioning of the CREANDO platform revolves around the creation and edition of stories through the customization of the TwineJS tool, which allows generating a personalized user interface for a specific project.

CREANDO is composed by a story editing tool and a mobile multiplatform application for accessing the story editor and the different tools that facilitate the design of pervasive gaming experiences, including augmented reality, the reading of QR codes and Indoor location using Beacon devices. The tool has a management panel of the stories created for its edition, or the generation of a new game experience. Later, when you want to generate a new game experience you can create a graph with the different scenarios and challenges that the experience exposes to the player (Fig. 6).

Each of the nodes that are in the graph of the game experience can contain different digital elements, from HTML code to QR code readers and augmented reality modules.

When the game experience is configured, it is possible to execute the game experience from the mobile application. The mobile application Creando is the container where the tools that facilitate the pervasiveness of experiences are grouped, such as augmented reality, QR codes and indoor positioning (Fig. 7). In the next section we will explain a built prototype with the platform in an educational environment.

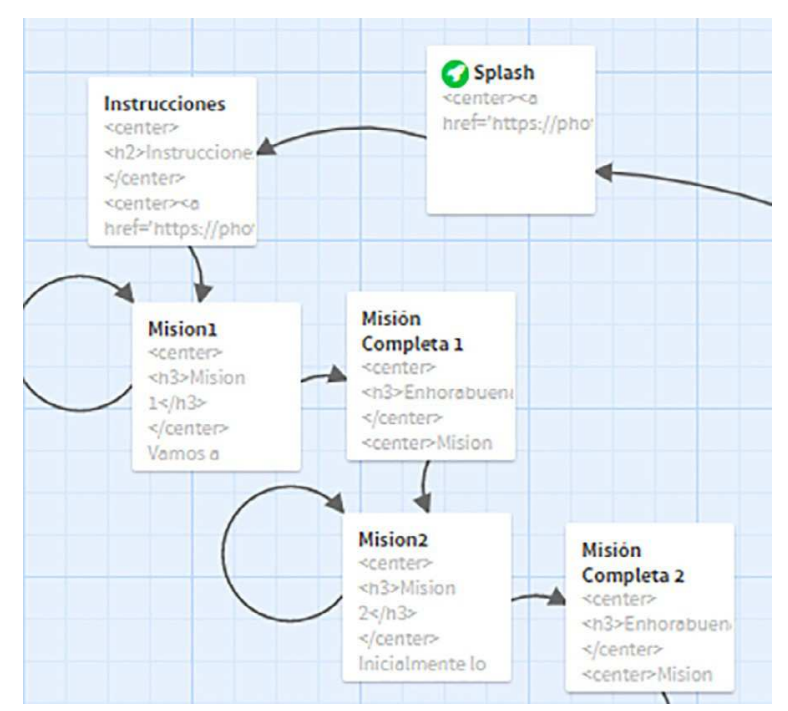

Fig. 6. Story graph divided by scenes to edit challenges and content. 


\section{Creando +}

\begin{tabular}{|c|}
\hline HISTORIAS \\
\hline LECTOR CODIGOS QR \\
\hline LECTOR MARCADORES AR \\
\hline DETECTOR BLE BEACONS \\
\hline
\end{tabular}

Fig. 7. Screenshot of the main menu in the mobile app.

\section{Study case "Unicauca aprende - Creando"}

With the need expressed in previous sections, where the increase in students' motivation in learning processes is at the center of the research, this prototype is constructed and tested to serve as proof of the platform's functioning, in addition, the goal related to motivation is met. Consequently, it is also necessary to make measurements of the gameplay presented by the game experiences created from the platform. That is why it is added the results obtained in the measurement of different kinds of gameplay for the developed game experience.

In the study case, the first semester students from the systems engineering program of the University of Cauca were taken into account. This is done with the premise of the high dropout rate and low performance, where the central reason is the change of teaching paradigm, especially in the subjects related to programming area.

Due to the above, it was proposed to carry out a pervasive gaming experience that allows the introduction to the first semester students of the systems engineering program of the University of Cauca. This with the mood to measure their previous knowledge in the area of programming and computing. And as an additional value, through a spatial and social pervasiveness, each one of the spaces of the university is taught through the narrative included in the game experience.

In the design of the history of the experience was used as a guide the game design document (GDD) built in the project JUG- UEMOS of the Spain government. This document is part of the doctoral thesis of Arango-López, who has adjusted it as the Design Document of the Game Experience to fulfill the characteristics of the narrative in geolocalized pervasive games.

\subsection{Game story}

The gaming experience called "Unicauca aprende - Creando Systems Engineering" is a treasure hunt type. It is aimed at students in the first semester and takes place on the campus of the university, which is composed of different faculties and buildings dis- tributed throughout the city. The mechanics of the game is the follow-up of instructions with the purpose of collecting the in- formation related to lines of code, which allows to advance between the levels sequentially until reaching the last point of the route. In the last phase the collected lines will be used for the execution of a computer program.

The goal of the gaming experience is to make known key aspects for the students about the university and the career they initiate. Consequently, the execution of new methods that support the learning process is accomplished, which increase the level of moti- vation in them. Also, through this experience the context is presented and it approaches the basic concepts of programming logic through non-traditional methods. A differentiating aspect of the experience is the use of tools that facilitate pervasiveness for the development of the game.

The strategy for students to know the university campus and its dependencies during the gaming experience is based on spatial pervasiveness, which causes students to move through the real world according to the indications given by the narrative included in the game.

The aesthetics of the game is based on a virtual student guide; this is in charge of accompanying the player during the execution of the game experience. In addition, it provides information about the history of computing and leads the student to visit the different spaces of the university campus during the experience until it ends.

The game world is a mixture between real world and virtual world, the virtual guide of the game makes a tour along with the player on the campus of the university where there is access to virtual and real objects. The elements of interaction between the real world and the virtual world are the QR codes distributed by the campus that present information to the player in the form of text or links to web pages that provide information about programming, computing and execution of lines of code. The bluetooth beacons present notifications for access to repositories with content related to the experience, the AR markers present augmented reality content to the player regarding the theme of the gaming experience.

\subsection{Results}

The elements of interaction to facilitate the pervasiveness used in the experience were the beacons of Estimote, AR markers and 


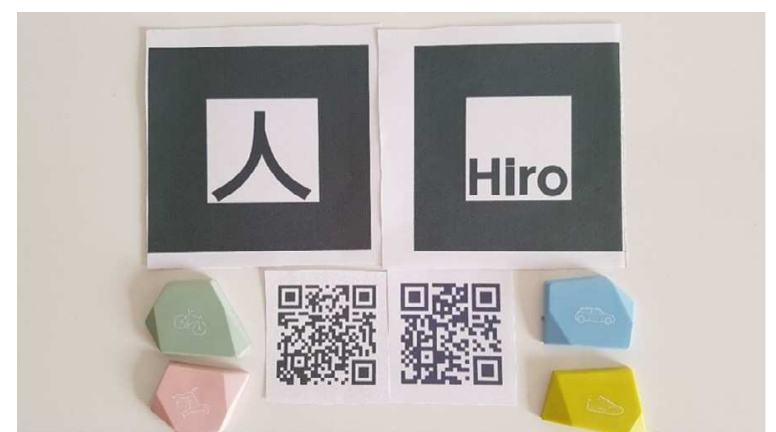

Fig. 8. Elements used to facilitate the interaction between the player and the game experience.

QR codes (Fig. 8).

During the execution of the gaming experience, the immersion of the students in the presented history was evidenced, expressed in their level of motivation in each of the levels and the expectation for the following scenarios and elements with which they interacted. In fact, the technological components used for the construction of the gaming experience at a pervasive level were fundamental for students' immersion and adaptation to the contents. Some of the interactions with the elements of the story such as QR codes, Beacons and AR markers are presented in Fig. 9.

The interaction graph of the "Unicauca aprende - Creando" experience presented in Fig. 6, it is based on the treasure hunt game methodology, where the player is presented with a welcome screen, an instruction screen and 6 sequential missions that represent the narrative of history.

In order to advance, the condition of success that is within the information presented by the elements of interaction must be accomplish. In case of not entering the correct condition, the player remains in the current mission until the level is met. While the player advances between the levels, the player has to perform the collection of elements for the solution of the final mission. At the end of the 6 missions, a screen of End of the game is presented to the player.

\subsection{Playability metrics and validation}

In order to validate the educational contribution of the experience, a diagnostic survey was carried out to know the perception and knowledge of the students. Later, after performing the gaming experience, another survey was conducted to measure the ef- fectiveness of the experience and to obtain the results about the motivation of the students. These surveys were conducted by 20 students belonging to the target population.

The most significant result was the increase in motivation, from an initial $65 \%$ to a final $90 \%$ above 3 on a scale of $1-5$. In addition, students who initially declared themselves with low motivation (values of 1 and 2 in the aforementioned scale) they increased their motivation, this is evidenced in Fig. 10, where it is shown that after the execution of the user experience there are no longer students in these categories of the scale.

Another representative result related to student learning can be evidenced in the percentage increase to $75 \%$ over a score of 2 . Also, it is important to consider that $40 \%$ of the respondents before the gaming experience declared no knowledge over this area, and after the experience, this population was reduced to $0 \%$. In this analysis it can be said that the knowledge average was increased by $30 \%$. These analyzes are shown graphically in Fig. 11.

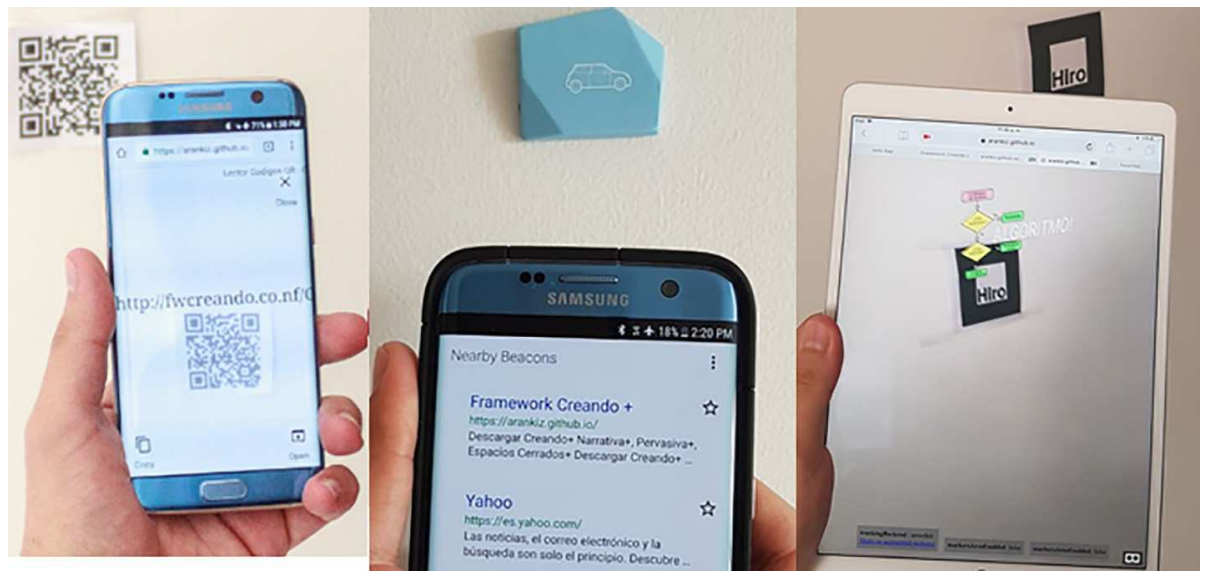

Fig. 9. Different interactions with the elements in the game experience. 

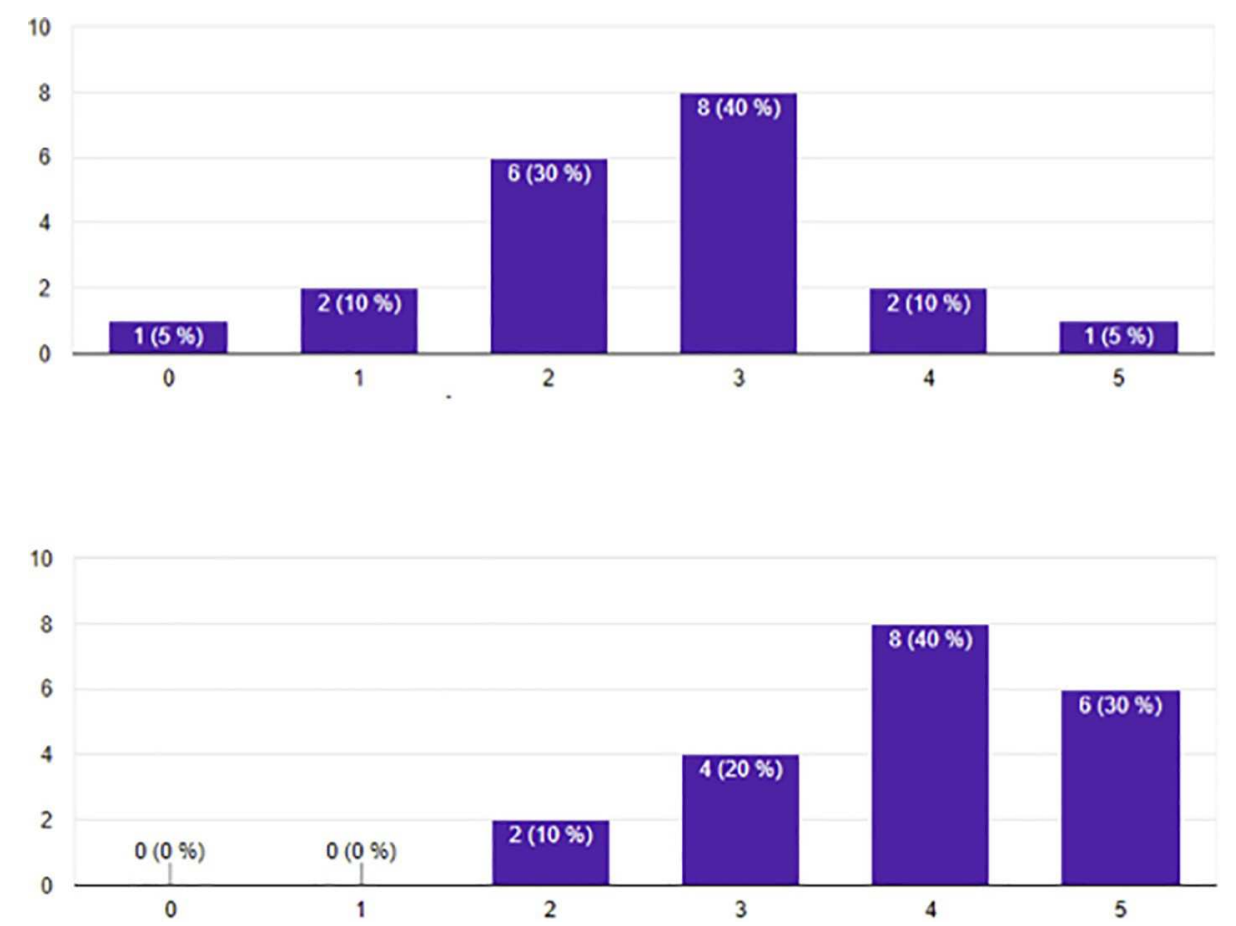

Fig. 10. Motivation level before and later of participating in the game experience.
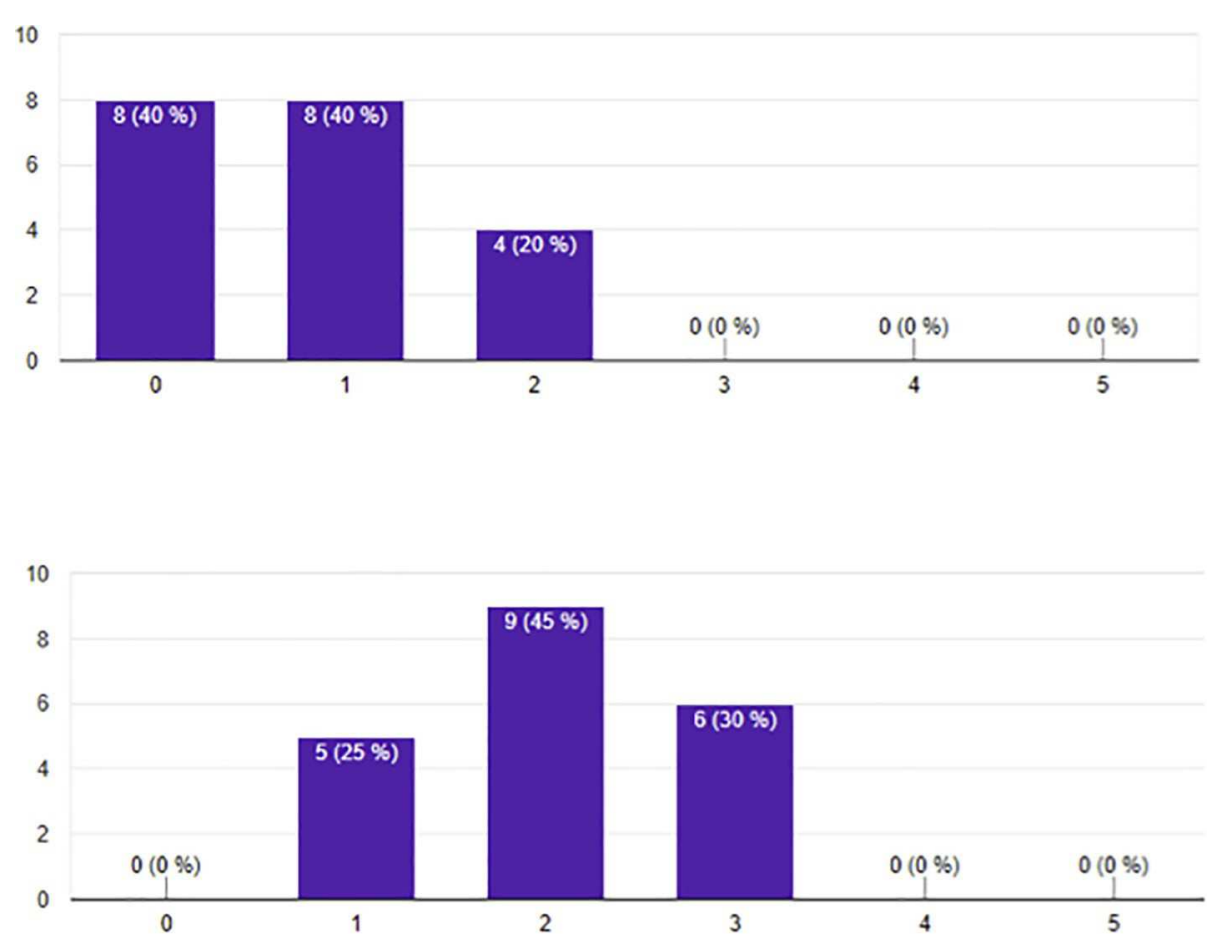

Fig. 11. Knowledge about computation basis before and later of participating in the game experience.

Motivation and knowledge are a fundamental part of the success of the investigation. But, when you build gaming experiences, it is also essential to measure the gameplay that they present and the players' perception of their components. This serves to evolve and improve aspects that can lead to a positive impact in later stages of experimentation. For this reason, the Playability metrics presented by Gonzáles-Sánchez were applied in Sánchez (2012), González Sánchez and Gutiérrez Vela (2014). These metrics focus on 6 types of playability: intrinsic, mechanical, interactive, artistic, personal and social. In addition, 7 attributes of the playability are considered 
Table 1

Examples of applied questions to measure the playability.

\begin{tabular}{ll}
\hline Facets of Playability & Evaluation Heuristics \\
\hline Intrinsic & $\begin{array}{l}\text { The game mechanics are fun and interesting for the player } \\
\text { The game can be replayed by offering new challenges } \\
\text { The game can be played without using the help manual }\end{array}$ \\
Mechanical & The game engine satisfies the player and exploits the full platform resources \\
& The game provides a balanced IA system to readapt the challenges to the player actions \\
& The game offers dynamic context-sensitive help for overcoming a specific challenge. \\
Artistic & The game story and narrative are pleasing to the player. \\
& The game story catches the player's attention and the important elements are remarked during the play time. The \\
& game music is consistent with the challenges and immerses the player in the game dynamic. \\
Intrapersonal & New game objectives, rules and challenges are easily identified with several players playing the game. \\
& The 'full' game story is complete for all players or can be completed by every player sharing the story events. The \\
social interaction among other players or characters in the new dynamic of play is attractive to the player.
\end{tabular}

for each proposed type: satisfaction, learning, efficiency, immersion, motivation, emotion and socialization. Some of the questions related to these metrics are shown in Table 1.

In this process the same participants of the game experience were consulted, this process was carried out after the survey on motivation and knowledge in the computer area. The results obtained satisfy the playability characteristics that a gaming experience must have with levels of pervasiveness.

Initially, a count was made of the answers given by the 20 participants, from there the general average was obtained for each one of the types of gameplay and the corresponding attributes. Next, Table 2 presents the results obtained after conducting the gameplay surveys about the built prototype.

Subsequently, analyzing the results in each of its types of playability and attributes, representative graphs of the relationship between these components have been obtained. Below are some examples of such graphs and the individual analysis of each of them.

Fig. 12 shows the relationship that exists between the different attributes in the personal gameplay. This graph affirms what is found in the analysis of students' motivation and knowledge learning in the computer area, since they are the attributes that stand out.

On the other hand, the Fig. 13 shows the most representative attributes of interactive gameplay are motivation and immersion, as well as the learning attribute. It is a characteristic to take into account in the evolution of the prototype, where it should focus more on collaborative learning.

Finally, we decided to perform the analysis of the motivation attribute for each type of gameplay, since it is the focus of the study (See Fig. 14). This analysis shows that the motivation is greater in artistic gameplay, followed by personal, social and interactive gameplay. There is a low level of motivation in the intrinsic and mechanical gameplay, which must be taken into account to improve in the next versions.

\section{Conclusions and future work}

In this research the implementation of the CREANDO platform has been presented, which allows the creation and edition of game experiences based on the narrative and focused on the learning process. In addition, the presented solution is generated from the mixture of different tools tested and integrated to achieve an optimal result at low cost.

Table 2

Obtained results later of apply the playability metrics - types vs attributes.

\begin{tabular}{lccccccc}
\hline Facets of Playability & $\mathrm{Sa}^{1}$ & $\mathrm{~L}^{2}$ & $\mathrm{Ef}^{3}$ & $\mathrm{I}^{4}$ & $\mathrm{M}^{5}$ & $\mathrm{Em}^{6}$ & $\mathrm{AVG}^{7}$ \\
\hline Intrinsic & 4.16 & 4.21 & 4.33 & 4.21 & 4.12 & 4.24 & 4.32 \\
Mechanical & 4.18 & 4.38 & 4.00 & 4.21 & 4.30 & 4.23 & 4.02 \\
Interactive & 4.04 & 3.98 & 3.97 & 4.52 & 4.50 & 4.23 & 4.27 \\
Artistic & 4.16 & 4.18 & 4.33 & 4.20 & 4.60 & 4.05 & 4.11 \\
Personal & 4.15 & 4.43 & 4.33 & 4.34 & 4.43 & 4.17 & 4.12 \\
Intrapersonal & 4.18 & 4.35 & 4.29 & 4.25 & 4.46 & 4.00 & 4.16 \\
AVG & 4.15 & 4.25 & 4.21 & 4.29 & 4.40 & 4.15 & 4.23 \\
\hline
\end{tabular}

1 Satisfaction.

2 Learning.

3 Efficiency.

${ }^{4}$ Immersion.

5 Motivation.

${ }^{6}$ Emotion.

7 Socialization 


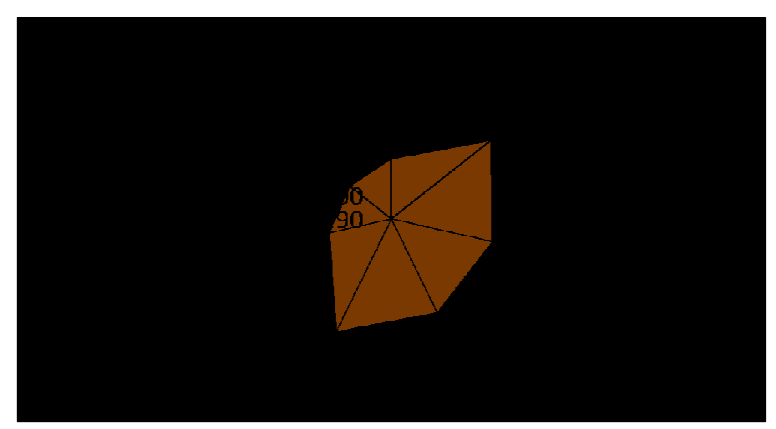

Fig. 12. Personal playability attributes.

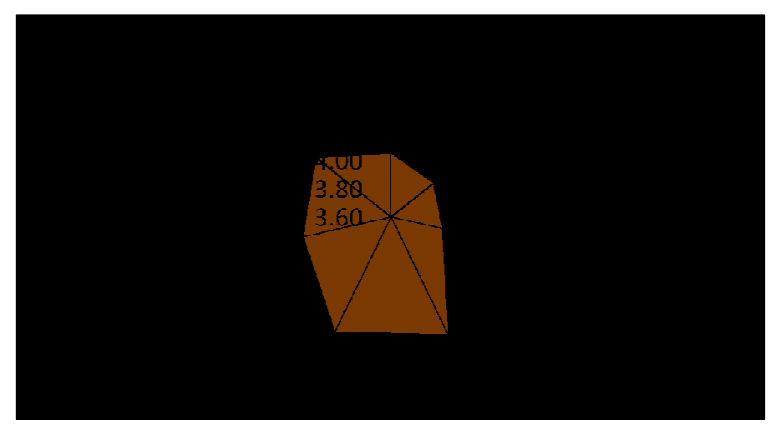

Fig. 13. Interactive playability atributes.

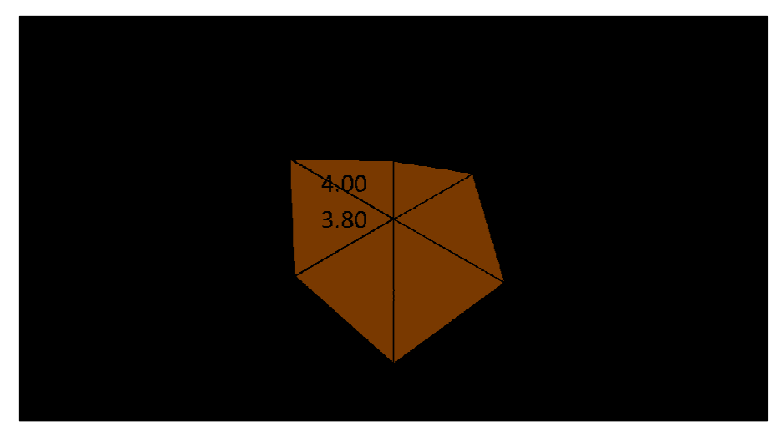

Fig. 14. Attributes in the motivation playability type.

It has been found that the use of pervasive gaming experience built under a higher education environment generates an increase in student motivation. Also, it has been detected that the increase in motivation positively impacts the learning process, this has been demonstrated through the previous and subsequent diagnoses to the development of the gaming experience with the students. It has shown the digital transformation like a correct way to change the traditional methods of teaching. Taking into account the acceptance that young people have for new technologies, it is important to continue in this line to create strategies to deliver knowledge to higher education students.

In this same line, it is defined that the narrative is important in the design and development of pervasive game experiences in an educational context, because a student has a greater experience of immersion and motivation to follow the thread of the story to continue getting the challenges presented by this.

The user experience becomes a fundamental part of the game experiences, since a user-centered design generates a greater degree of acceptance by the players. It is necessary to consider heuristics that support the development of better experiences, which will surely produce an increase in motivation and immersion in the gaming experience by students.

The creation of experiences of pervasive games in educational environments support the teaching-learning process in the classroom. Traditional methodologies must be supported in new technologies so that students feel part of the world of teaching. That is why you must have a methodological and technological evolution in the classrooms according to the one presented by society.

In fact, taking into account that pervasiveness has special characteristics that make the limits of the virtual world expand by making objects and people part of the gaming experience, the learning and motivation process must be adapted so that they become part of the life of the student in a natural way.

On the other hand, the metrics applied help us to conclude that the PGs positively support the process of motivation, socialization 
and immersion of students in the teaching-learning process. Also, it is important to consider the weak points that these show us to strengthen new experiences and obtain better results.

As future work, it is proposed to carry out enriched game experiences for specific areas of knowledge. Where the effectiveness and fun in each of these is evaluated, and the levels of pervasiveness can be classified in percentages of effectiveness for each of its attributes. Also, it is important to generate and apply specific metrics for each pervasive expansion in gaming experiences, and to evaluate the characteristics that should be considered for each case.

\section{Acknowledgement}

This work has been funded by the Ministry of Economy and Competitiveness of Spain, Spain as part of the JUGUEMOS project (TIN2015-67149-C3).

\section{References}

Arango-López, J., Collazos, C.A., Gutiérrez Vela, F.L., Castillo, L.F., 2017. A systematic review of geolocated pervasive games: a perspective from game development methodologies, software metrics and linked open data. vol. 10289, pp. 371-382.

Arango-López, J., Gutiérrez Vela, F.L., Collazos, C.A., Moreira, F., 2018. Modeling and defining the pervasive games and its components from a perspective of the player experience. In: WorldCIST'18 2018. Advances in Intelligent Systems and Computing, vol. 746, pp. 625-635.

Arango-lópez, J., Gutiérrez, F.L., Collazos, C.A., Valera, R., Cerezo, E., 2017. Pervasive games: giving a meaning based on the player experience. Interacción 2017, 1-4. González Sánchez, J.L., Gutiérrez Vela, F.L., 2014. Assessing the player interaction experiences based on playability. Entertain. Comput. 5 (4), $259-267$.

Gutierrez, L., et al., 2011. fAR-PLAY : a framework to develop augmented/alternate reality games. Percomorg 531-536.

Hinske, S., Lampe, M., Magerkurth, C., Röcker, C., 2007. Classifying Pervasive Games: On Pervasive Computing and Mixed Reality. In: Concepts Technol. Pervasive Games A Read. Pervasive Gaming Res., no. September 2017, pp. 11-38.

Huizinga, J., 1944. Homo Ludens: A Study of the Play-Element in Culture.

Jantke, K.P., Hume, T., 2015. Effective learning through meaning construction in digital role playing games. In: Consum. Electron. (ICCE), 2015 IEEE Int. Conf., pp. 653-656.

Kuk, K., Ilic, S., Spalevic, P., Panic, S., 2012. Student knowledge diagnosis in game-based learning applications. Intell. Syst. Inf. (SISY) $455-459$.

López-Arcos, J.R., Gutiérrez Vela, F.L., Padilla-Zea, N., Paderewski Rodríguez, P., 2016. Diseño de una narrativa interactiva para experiencias geolocalizadas. In: Xvii Congr. Int. Interacción Pers. 2016, pp. 25-32.

López-arcos, J.R., Gutiérrez Vela, F.L., 2016. Introducing an interactive story in a geolocalized experience. Int. Conf. Proc. Ser.

López-arcos, J.R., Gutiérrez Vela, F.L., 2016. Introducing an interactive story in a geolocalized experience *. Int. Conf. Proc. Ser.

Macvean, A., et al., 2011. WeQuest: Scalable Alternate Reality Games Through End-User Content Authoring. In: Proc. 8th Int. Conf. Adv. Comput. Entertain. Technol., p. Article No.: 22

Magerkurth, C., Cheok, A.D., Mandryk, R.L., Nilsen, T., 2005. Pervasive games: bringing computer entertainment back to the real world. ACM Comput. Entertain. 3 (3), $1-19$.

Maia, L.F., et al., 2017. LAGARTO: A LocAtion based games AuthoRing TOol enhanced with augmented reality features. Entertain. Comput.

Meadows, M.S., 2002. Pause \& Effect: The Art of Interactive Narrative.

Padilla-Zea, N., Gutiérrez, F.L., López-Arcos, J.R., Abad-Arranz, A., Paderewski, P., 2014. Modeling storytelling to be used in educational video games. Comput. Human Behav. 31 (1), 461-474.

Sánchez, J.L.G., et al., 2012. Playability: analysing user experience in video games. Behav. Inf. Technol. 31 (10), $1033-1054$.

Stach, C., Schlindwein, L.F.M., 2012. Candy Castle - A prototype for pervasive health games. In: 2012 IEEE Int. Conf. Pervasive Comput. Commun. Work. PERCOM Work. 2012, pp. 501-503.

Stach, C., Schlindwein, L.F.M., 2012. - Candy castle - a prototype for pervasive health games. In: IEEE International Conference on Pervasive Computing and Communications Workshops, pp. 501-503.

Tüysüz, C., 2009. Effect of the computer based game on pre-service teachers' achievement, attitudes, metacognition and motivation in chemistry. Sci. Res. Essays 4 (8), 780-790.

Viana, R., Ponte, N., Trinta, F., Viana, W., 2014. A systematic review on software engineering in pervasive games development. Proc. SBGames 742-751. 